\section{$\underset{\substack{\text { hommes } \\ \text { \& migrations }}}{ }$}

\section{Hommes \& migrations}

Revue française de référence sur les dynamiques

migratoires

1332 | 2021

Ce qui s'oublie et ce qui reste

\title{
Karim Akouche, Déflagration des sens
}

Paris, Écriture, 2020, 208 p., $18 €$.

\section{Mustapha Harzoune}

\section{Q OpenEdition \\ 1 Journals}

\section{Édition électronique}

URL : https://journals.openedition.org/hommesmigrations/12455

DOI : 10.4000/hommesmigrations. 12455

ISSN : 2262-3353

\section{Éditeur}

Musée national de l'histoire de l'immigration

\section{Édition imprimée}

Date de publication : 1 janvier 2021

Pagination : 265

ISBN : 978-2-919040-54-4

ISSN : 1142-852X

Référence électronique

Mustapha Harzoune, « Karim Akouche, Déflagration des sens », Hommes \& migrations [En ligne], 1332 | 2021, mis en ligne le 01 janvier 2021, consulté le 26 juillet 2021. URL : http://journals.openedition.org/ hommesmigrations/12455; DOI : https://doi.org/10.4000/hommesmigrations.12455 


\section{Déflagration des sens}

Karim Akouche, Paris, Écriture, 2020, 208 p., $18 €$.



Les thèmes abondent : immigration, islamisme (" l'islamisme, c'est l'islam en ébullition. L'islam, c'est l'islamisme mis au frigo »), victimisation (le «totem de la victime » comme l'appelait déjà Samir Kassir), islamophobie (expédié par l'explicite «Toz » kabyle, soit « mon cul! »), colonisation et ressentiment («Arrête de remuer le passé, camarade. [...] Sors du complexe du colonisé, sois adulte et responsable. Quitte la fourrure du ressentiment »). Sans oublier, puisque le narrateur est un rejeton du Djurdjura, la question de l'identité algérienne (« Si tu veux dominer un peuple, fais-lui oublier ses racines $\gg)$...

Il s'agit d'un long monologue débité d'une traite, comme un trop-plein, une nécessité vitale de témoigner - d'être enregistré. Le narrateur se fait appeler Kâmal Sûtra (pour Kamal Storah). Il est né en Kabylie, a connu une enfance sans père - «papa forniquait en France avec sa deuxième femme ». Sa formation tient davantage à la sagesse du coin par sa mère transmise qu'aux élucubrations de l'école algérienne: "Je n'ai jamais été contre l'islam, c'est l'islam qui est contre nous. [...] Je suis un mécréant. J'ai cessé d'être musulman. [...] L'école algérienne voulait faire de moi un croyant, domptable à souhait, un soumis. Raté camarade. J'ai résisté avec mes moyens et, surtout, grâce à la chanson kabyle engagée et aux valeurs de mes ancêtres. » Ah le vitalisme et le lâcher prise à la sauce kabyle! C'est à lire.

Il a été journaliste (" métier de putassiers mal fourrés »), sans papiers en France et en Espagne et réexpédié fissa dans son cher pays. Après avoir fait de son fourgon Benz un véhicule de transport, il nourrit l'espoir de prospérer - et de servir le bien public - en transformant sa teutonne patache en un affriolant bordel ambulant. Il faut bien «qu'on laisse les jeunes se tripoter librement! » et "puisque le peuple se fanatise de plus en plus, autant le prostituer... ».

Le sexe ! Il est servi à toutes les sauces, dans toutes les positions, pour tous les goûts et toutes les espérances. Il est autant gymnastique des corps qu'idéal platonique. Il est ce non-dit qui nimbe regards et effleurements, cette absence qui gouverne les âmes prisonnières et qui fait les vies tristes. Et les sociétés mortes! 44 ans et encore puceau! Diagnostic imparable. Sur l'homme et sa société. Le « on ne peut pas réfléchir les couilles pleines » qui ouvre ce roman jubilatoire annonce la couleur : la dialectique du dire et de l'entendement. Provocation? Non! Plutôt procédé romanesque, maïeutique du verbe et du sens poussée jusqu'à ses limites pour accoucher de ce constat: Homme infécond. Indépendance inféconde. Pays infécond. On est loin des galipettes - réelles ou fantasmées - de Kâmal Sûtra. «On m'a dit des choses et des conneries, de prier et de chanter l'éloge de nos prédécesseurs. Tant d'ordres et d'interdits entassés dans mon sang et ma graisse... Je suis à la fois lourd et vide. J'ai un diable au corps et un idiot dans le cerveau. »

Sous le brio des formules et des raccourcis, l'art de l'insulte et l'érotisation, derrière la légèreté rabelaisienne et le poids du blasphème, le texte multiplie références philosophiques et littéraires. Les phrases sont sans concession, sans romantisme, sans simagrée et sans espoir. Plutôt Cioran que la mièvrerie des bonimenteurs.

Et plutôt Dionysos que Descartes : éloge du rire et du «bordel de la vie », éloge avec Baudelaire de l'ivresse, de la folie avec Kerouac dans un monde qui meurt d'un trop-plein de sérieux, gloire aux « cinglés » : Miller, Bukowski, Koestler... Et gloire à la littérature ! Jonathan Livingston le goéland ressuscitera notre homme. La Boétie, « Invictus » de William Ernest Henley lui ouvriront les voies de l'émancipation. La littérature ne change peut-être pas le monde, mais sa vie, sûrement!

Avant d'être un polémiste, Karim Akouche est un poète. Les mots, le souffle, le vitalisme tout terrain, la soif inextinguible d'amour et de liberté, tout cela, et plus encore, " est là, caché entre les dents fragiles des poètes, tout dégouline des doigts des peintres maudits ». Alors oui, plutôt « divaguer» avec le poète que de marcher au pas d'une soldatesque trop bien huilée.

M. H.

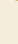

